\title{
Liquid antisolvent precipitation process for solubility modulation of bicalutamide
}

TARIQUE ALI MEER

KIRAN P. SAWANT

PURNIMA D. AMIN*

Department of Pharmaceutical Sciences and Technology, Institute of Chemical Technology, Matunga, Mumbai-400019 India

Accepted October 12, 2011

\begin{abstract}
Liquid antisolvent process was explored as a solubility modulating tool. Bicalutamide, a poorly water soluble drug, was used as a candidate. Low aqueous solubility and poor dissolution of bicalutamide results into poor and variable bioavailability. Therefore, the objective of the present work was to modify the solubility of bicalutamide using the liquid antisolvent precipitation process. HPMC E5 and Poloxamer 407 were shortlisted as a hydrophilic polymer and surfactant, respectively, for the process. Process optimization was done with respect to the hydrophilic polymer, surfactant and drug loading concentration. The resultant microcrystals were characterized with various instrumental techniques for material characterization such as IR, DSC, SEM, XRD, particle size, specific surface area and dissolution kinetics.
\end{abstract}

Keywords: bicalutamide, solubility enhancement, dissolution rate, liquid antisolvent precipitation

Bicalutamide, N-[4-cyano-3-(trifluoromethyl)phenyl]-3-[(4-fluorophenyl)sulfonyl]-2-hydroxy-2-methylpropanamide, is a nonsteroidal antiandrogen mainly used for the treatment of prostate cancer (1) and is orally active (Fig. 1). It has the ability to competitively block the growth-stimulating effects of androgens on prostate cancer (2). Though bicalutamide has become popular for the treatment of prostate cancer, it has certain demerits such as high lipophilicity and poor aqueous solubility (3). Drugs with poor aqueous solubility generally show variable absorption (4). The low aqueous solubility of bicalutamide may be due to its polymorphism and hence the drug has been classified as a BCS class II (low solubility and high permeability) drug according to the biopharmaceutical classification system (5). The very low solubility of bicalutamide accounts for dissolution as its rate determining step for bioavailability. Improved dissolution rate can be expected to increase oral bioavailability of the drug, resulting in reduction of dosing frequency and improved patient compliance (6).

\footnotetext{
* Correspondence; e-mail: purnima.amin@yahoo.co.in
} 


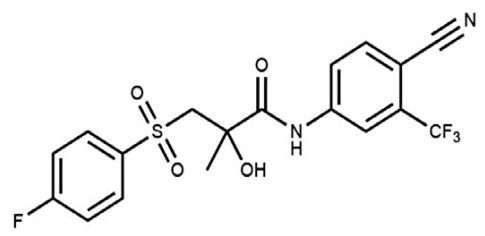

Fig. 1. Structure of bicalutamide.

Numerous approaches have been reported in literature for solubility enhancement; they include particle size reduction (7), surfactant incorporation (8), inclusion complexation (9), microencapsulation (10), solid solutions (11) and prodrug formulation (12).

This work was aimed to investigate the solubility enhancement of bicalutamide using liquid antisolvent precipitation process (LASPP) and subsequently to improve its dissolution profile. Liquid antisolvent precipitation process basically involves precipitation of a solid solute previously dissolved in an organic solvent by adding it into a non-solvent (antisolvent) under stirring. The process is preferably carried out in the presence of some steric and electrostatic stabilizers such as hydrophilic polymers and/or surfactants. During precipitation, these hydrophilic polymers and surfactants help in increasing the nucleation rate, thereby inhibiting particle growth and thus producing submicronic particles.

\section{EXPERIMENTAL}

\section{Materials}

Raw bicalutamide was obtained from Hetero drugs, India. Hydroxypropyl methylcellulose (HPMC E5) was provided by Colorcon, India. Polyvinyl pyrrolidone vinyl acetate copolymerisate K28 (Kollidon VA64), ethylene oxide propylene oxide block copolymer (Poloxamer 407), polyvinylpyrrolidone K90 (PVPK90), polyoxyethylene glycerol triricinoleat 35 (Cremophor EL) and macrogol 15 hydroxy stearate (Solutol HS 15) were kindly donated by BASF Co., Germany. Polyvinylalcohol (PVA, $\left.M_{\mathrm{r}} 31,000-50,000\right)$ was a gift from Nippon (Japan), labrasol was a gift from Gattefosse (France), polyoxy ethylene (20) sorbitan monolaurate (Tween 20), polyoxy ethylene (80) sorbitan monolaurate (Tween 80) were purchased from Merck (India). Acetone and sodium lauryl sulphate (SLS) was purchased from S. D. Fine Chemicals (India). Aerosil 200 was obtained from Degussa (Germany). Sodium starch glycolate was procured from Roquette (France), and microcrystalline cellulose 102 (MCC) was obtained from FMC Biopolymers (Ireland).

\section{Preparation of microcrystal particles}

Bicalutamide microcrystal particles were prepared using an antisolvent precipitation process. Bicalutamide $90 \mathrm{mg}$ was completely dissolved in $1 \mathrm{~mL}$ of acetone. The prepared drug solution was added dropwise into $20 \mathrm{~mL}$ water containing $0.3 \%(\mathrm{~m} / \mathrm{V})$ of each poly- 
mer and surfactant under stirring at $3000 \mathrm{rpm}$. Precipitation of drug particles occurred immediately upon mixing and formed a suspension with a milky appearance. The suspension was centrifuged at $10000 \mathrm{rpm}$ for $10 \mathrm{~min}$ a (centrifuge Eltek TC4100 D, India) and washed twice with $50 \mathrm{~mL}$ distilled water. The obtained particles were oven-dried at $60{ }^{\circ} \mathrm{C}$ overnight.

\section{Formulation of LASPP microcrystals into tablets}

Bicalutamide and LASPP microcrystals of bicalutamide were incorporated in tablets with the composition given in Table I.

Table I. Composition of tablets prepared for the dissolution study

\begin{tabular}{lc}
\hline Ingredient & mg per tab \\
\hline Bicalutamide / LASPP microcrystals & 50 \\
MCC 102 & 138 \\
Sodium starch glycolate & 10 \\
Aerosil 200 & 2 \\
\hline
\end{tabular}

MCC - microcrystalline cellulose

Tablets were compressed on a single station tablet compression machine (Cadmach, India), using the 8-mm standard concave punch with a crushing strength of 7 to $9 \mathrm{~kg} \mathrm{~cm}^{-2}$. The tablets so formed were used for the dissolution tests.

\section{Tablet dissolution studies}

Dissolution studies were performed following the USP apparatus 2 (paddle) method (13). The paddle rotation and bath temperature were set at $50 \mathrm{rpm}$ and $37.5 \pm 0.5{ }^{\circ} \mathrm{C}$, respectively. Each test was carried out in $1000 \mathrm{~mL}$ of $1 \%$ SLS dissolution medium for the sink condition. Bicalutamide tablets (prepared as shown in Table I) containing $50 \mathrm{mg}$ raw or LASPP bicalutamide microcrystals were placed in the dissolution medium. Then, 10-mL aliquot samples were withdrawn at specified time intervals and were filtered using $0.45-\mu \mathrm{m}$ polytetrafluoroethylene (PTFE) syringe filters. At each sampling time, an equal volume of the test medium was replenished. The filtrate was diluted ten times with the dissolution medium and quantified by UV spectrophotometric analysis at $273 \mathrm{~nm}$.

\section{Particle size measurement and specific surface area analysis}

Particle size and distribution with a specific surface area of samples were determined by dynamic light scattering using a laser diffractometer (Mastersizer 2000, Malvern Instruments, UK). The LASPP bicalutamide microcrystals were dispersed in distilled water. Each measurement was performed in triplicate (Table II). 


\section{Scanning electron microscopy (SEM)}

Morphology of the particles was observed using a scanning electron microscope (SEM; JSM-6380LA, Jeol, Japan). LASPP bicalutamide microcrystals samples were coated with gold and palladium using a vacuum evaporator and were examined using SEM at $15 \mathrm{kV}$ accelerating voltage.

\section{Fourier transform infrared spectroscopy}

FT-IR spectroscopy was conducted on a FT-IR spectrometer (Spectrum 100, Perkin Elmer, USA) using the attenuated total reflectance (ATR) method. Samples were well mixed with $\mathrm{KBr}$ powder and kept in a sample holder. The scanning range was $450-4000 \mathrm{~cm}^{-1}$ and the resolution was $4 \mathrm{~cm}^{-1}$. A total of 32 reference scans were performed.

\section{Thermal analysis}

DSC measurements were carried out in an instrument Pyris 6 DSC (Perkin Elmer). LASPP bicalutamide samples of $5 \mathrm{mg}$ were accurately weighed and sealed in an aluminium pan. The measurements were performed under a nitrogen purge flow rate of 20 $\mathrm{mL} \mathrm{min}^{-1}$ at $20-240^{\circ} \mathrm{C}$ at a heating rate of $10^{\circ} \mathrm{C} \mathrm{min}^{-1}$. An empty pan was used as reference and for calibration prior to each experiment.

\section{Powder X-ray diffraction analysis}

The XRPD patterns of bicalutamide samples were recorded in a Rigaku powder $\mathrm{X}$-ray diffraction system (Miniflex, Japan) with $\mathrm{Cu}-\mathrm{K} \alpha$ radiation. The samples were run over the most informative range from $0^{\circ}$ to $60^{\circ}$ of $2 \theta$. The step scan mode was performed with a step size of $0.02^{\circ}$ at a rate of $2^{\circ} \mathrm{min}^{-1}$.

\section{RESULTS AND DISCUSSION}

In this study, bicalutamide microcrystals were prepared using the liquid antisolvent precipitation process in the presence of a hydrophilic polymer and amphiphilic surfactant for the enhancement of the dissolution rate. Furthermore, the effective hydrophilic polymers and surfactants used were screened for their ability to produce a smaller particle size, and particles having more wettability, thereby resulting in enhanced dissolution rate. Raw bicalutamide and LASPP microcrystals were characterized in the solid state using several analytical techniques such as dynamic light scattering, scanning electronic microscopy, Fourier transformation-infrared spectroscopy, differential scanning calorimetry, powder X-ray diffraction analysis and dissolution test.

\section{Selection of hydrophilic polymer}

Screening was performed among different hydrophilic polymers including PVP K90, PVA 31000-50000, Kollidon VA64 and HPMC E5 in distilled water $(0.2 \%, m / V)$ at a constant drug concentration $\left(90 \mathrm{mg} \mathrm{mL}^{-1}\right)$. The microcrystals so formed were dried and in- 
corporated into tablets. Fig. 2a shows the dissolution profile of the different LASPP tablets; HPMC E5 was found most suitable for carrying out further LASPP optimization.

\section{Polymer concentration optimization}

Liquid antisolvent process was carried out by varying the concentration of HPMC E5. Fig. $2 b$ shows the effect of HPMC E5 concentration on the dissolution rate of bicalutamide. Increase in HPMC E5 concentration from 0 to $0.3 \%(\mathrm{~m} / \mathrm{m})$ resulted in gradual
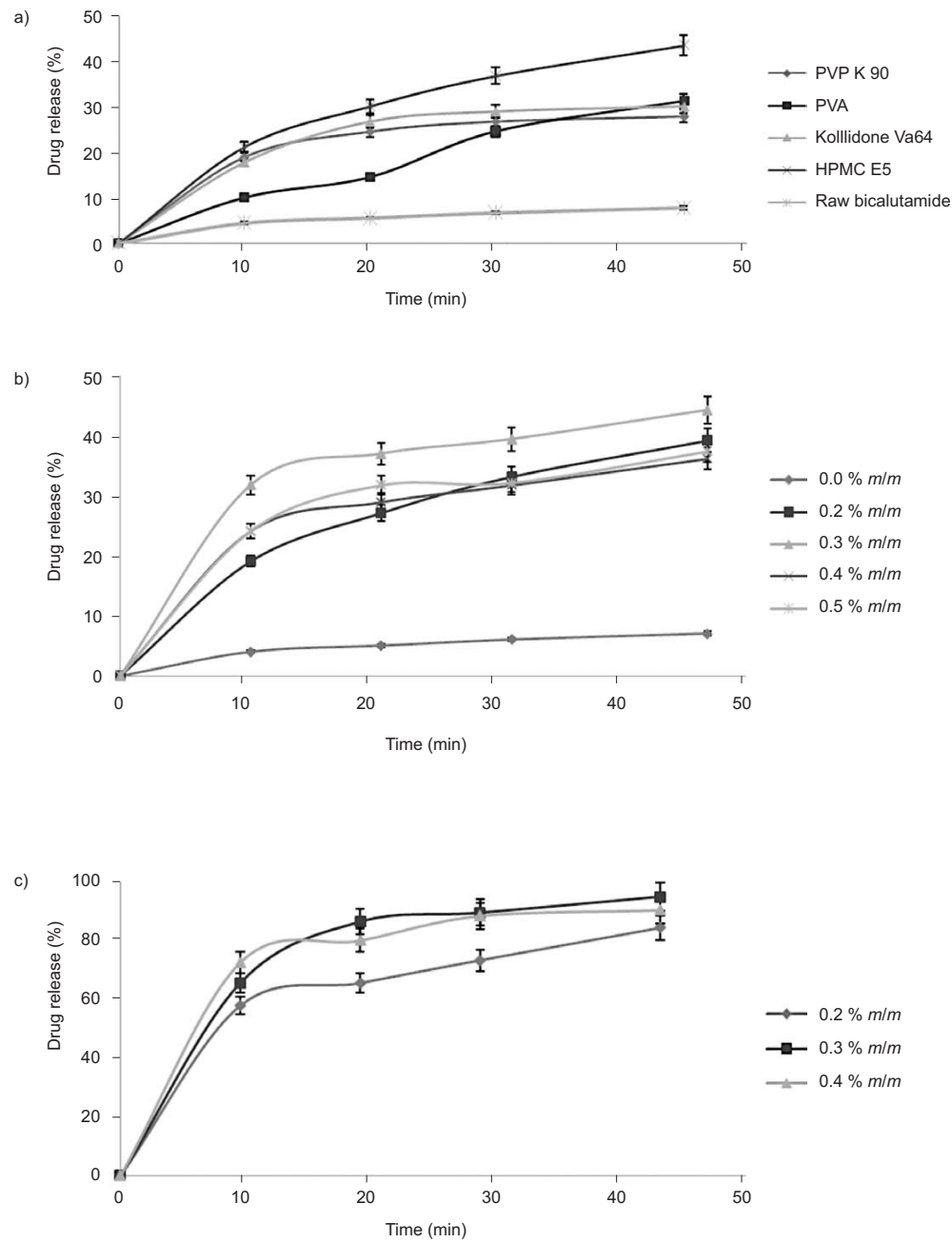

Fig. 2. Dissolution profile of LASPP bicalutamide/bicalutamide affected by: a) polymers; b) HPMC E5 concentration; c) Polaxamer 407 concentration (mean $\pm \mathrm{SD}, n=3$ ). 
increase in dissolution but beyond $0.3 \%(\mathrm{~m} / \mathrm{m})$ the dissolution gradually decreased. This could be due to the strong hydrophilic environment produced by the polymer, which allowed spontaneous displacement of the bicalutamide particles in solution leading to an increase in particle size.

\section{Screening and optimization of surfactants}

Different surfactants $(0.2 \%, \mathrm{~m} / \mathrm{m}$, in water) were tried, keeping HPMC E5 $(0.3 \%$, $\mathrm{m} / \mathrm{m}$, in water) and the drug (90 $\mathrm{mg} \mathrm{mL}^{-1}$ of acetone) at constant concentration to check their suitability for the LASPP bicalutamide crystals production. Fig. 3 shows the effect of various surfactants on dissolution of bicalutamide in 10 and $45 \mathrm{~min}$.

Fig. 2c shows the effectiveness of Poloxamer 407 for increasing the solubility of bicalutamide. The micellar regions of surfactants may be responsible for the provision of in-process nucleation of bicalutamide microcrystals, which in turn cause a controlled particle size decrease, subsequently leading to an increased surface area and increased dissolution (14). Concentration of Poloxamer 407 was varied $(0.2,0.3$ and $0.4 \%, \mathrm{~m} / \mathrm{m}$, but keeping HPMC E5 $(0.3 \%, m / m)$ constant. Fig. 2c shows the dissolution of LASP bicalutamide microcrystals.

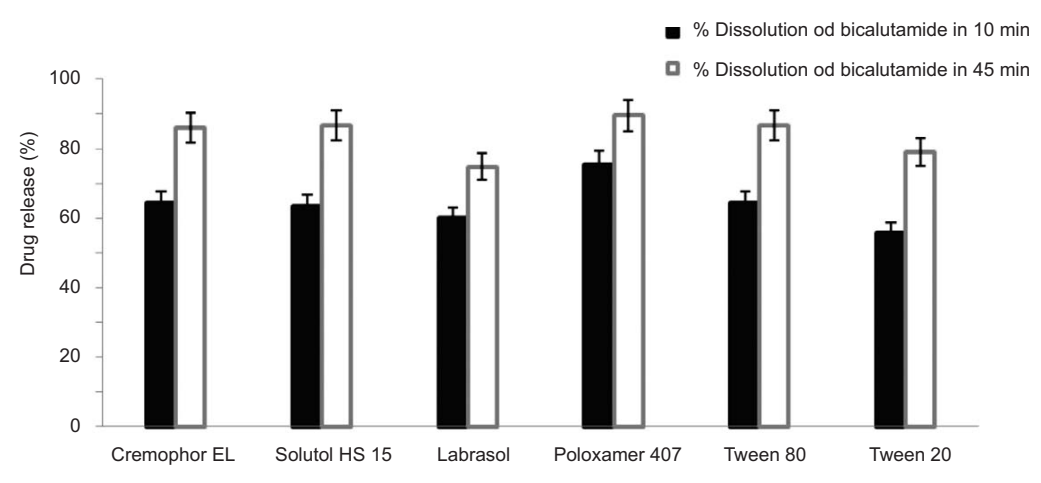

Fig. 3. Effect of various surfactants on the dissolution of LASPP bicalutamide (mean $\pm \mathrm{SD}, n=3$ ).

\section{Effect of drug loading}

Increase in drug concentration above $90 \mathrm{mg} \mathrm{mL}^{-1}$ increased the particle size. This could be due to an increase in viscosity which can prevent diffusion between solution and antisolvent and has been shown to result in non-uniform supersaturation and particle agglomeration (15).

\section{Morphology and particle size distribution}

SEM images of raw bicalutamide and LASPP bicalutamide microcrystal particles are shown in Fig. 4. The LASPP bicalutamide microcrystals appear uniform and spherical, 
while the raw bicalutamide appears needle-like with regularly shaped crystals, which are agglomerated and are of several microns in size.

Results from Table II show that addition of polymer and surfactant in aqueous phase had an effect on particle size reduction and thereby increased the surface area, when no polymer/surfactant was used in the process, the formation of granular structures took place.
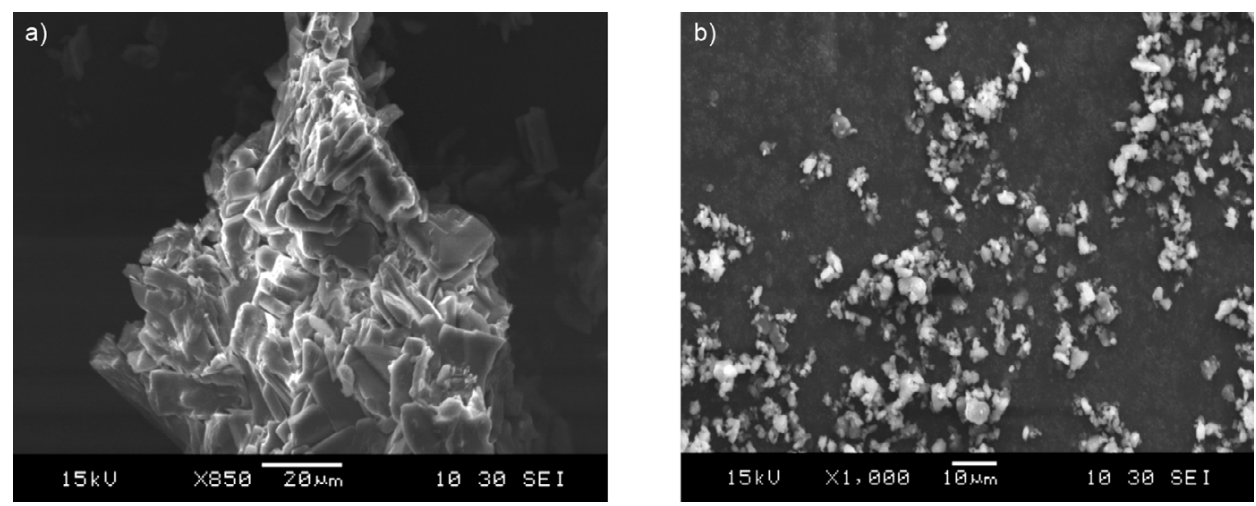

Fig. 4. SEM images of: a) raw bicalutamide, and b) LASPP bicalutamide microcrystals.

\section{DSC analysis and XRPD}

The changes in polymorphism and crystallinity of bicalutamide before and after the antisolvent precipitation process were assessed by comparing the DSC thermograms (Fig. 5) and PXRD patterns (Fig. 6) of plain and LASPP bicalutamide microcrystals.

The DSC thermograms of raw bicalutamide and LASPP bicalutamide microcrystals (Fig. 5) show a peak at $194-197^{\circ} \mathrm{C}$, which corresponds to the melting point of bicalutamide. As shown in Fig. 5, the enthalpy of LASPP bicalutamide micrystals was lower compared to that of raw bicalutamide, indicating decreased crystallinity for crystal particles obtained in the presence of polymer and surfactant. Also, there is an exothermic peak at $155{ }^{\circ} \mathrm{C}$ for LASPP bicalutamide microcrystals, which may be due to the recrystallization upon heating the drug. This additionally demonstrates the reduced crystallinity of LASPP bicalutamide microcrystals compared to raw bicalutamide (7).

Table II. Mean particle size and specific surface area of raw and LASPP bicalutamide

\begin{tabular}{lccc}
\hline Sample & $\begin{array}{c}\text { Mean particle } \\
\text { size }(\mu \mathrm{m})\end{array}$ & Span & $\begin{array}{c}\text { Specific surface } \\
\text { area }\left(\mathrm{g} \mathrm{cm}^{-2}\right)\end{array}$ \\
\hline Raw bicalutamide & 143.26 & 5.440 & 0.802 \\
LASPP microcrystal bicalutamide & 23.956 & 2.667 & 1.52 \\
\hline
\end{tabular}

a Span $=\left(d_{90}-d_{10}\right) / d_{50}$ 
Fig. 6 shows that both raw bicalutamide and LASPP bicalutamide microcrystals had the same polymorph with similar peak positions in the XRPD patterns. However, there were some differences between the two samples in relative integrated intensities of each peak. Percent crystallinity of raw bicalutamide and LASPP bicalutamide microcrystals was found to be 30.15 and 25.25 , respectively.
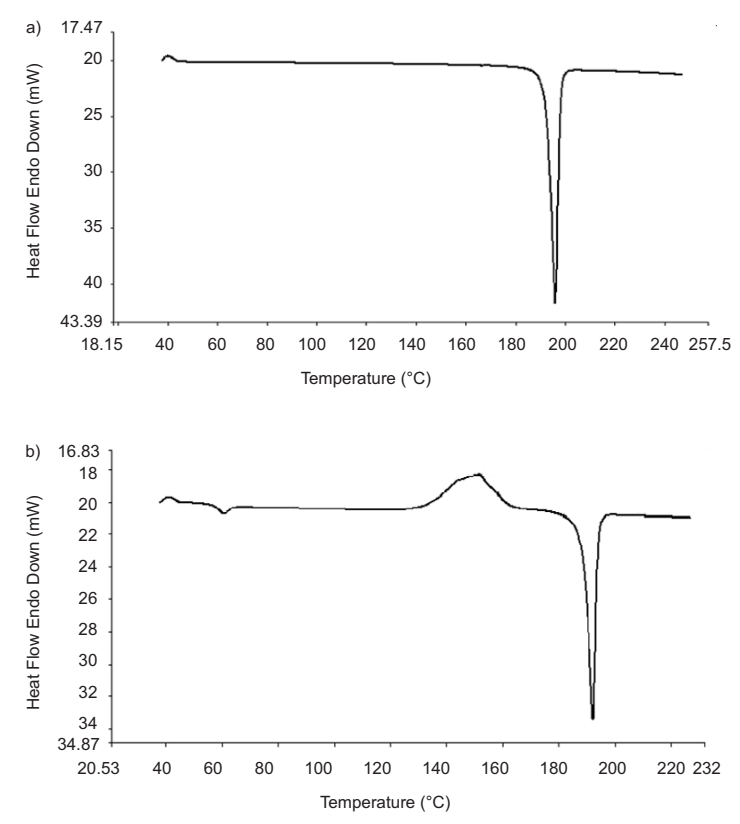

Fig. 5. DSC of: a) raw bicalutamide, and b) LASPP bicalutamide microcrystals.

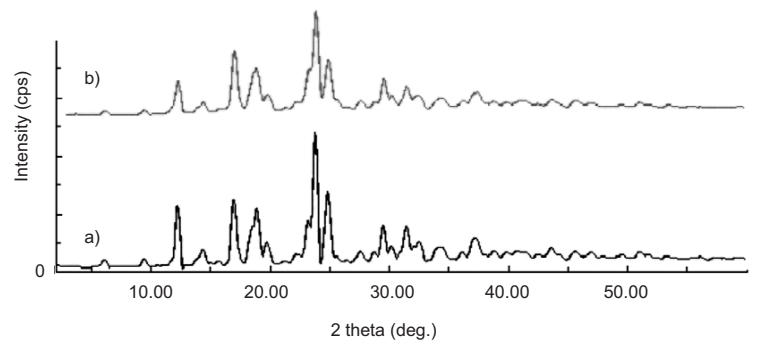

Fig. 6. XRPD of: a) raw bicalutamide, and b) LASPP bicalutamide crystals.

\section{FTIR analysis}

Fig. 7 shows FTIR spectra of raw bicalutamide and LASPP bicalutamide. Both are characterized by sulphate $\left(1517 \mathrm{~cm}^{-1}\right)$, hydroxyl group $\left(3581 \mathrm{~cm}^{-1}\right)$, carbonyl $\left(1689 \mathrm{~cm}^{-1}\right)$, $\mathrm{NH}\left(3338 \mathrm{~cm}^{-1}\right)$ and nitrile $\left(2230 \mathrm{~cm}^{-1}\right)$. The identical FTIR spectra of raw bicalutamide and LASPP bicalutamide suggested that there was no change in bicalutamide molecular structure. 

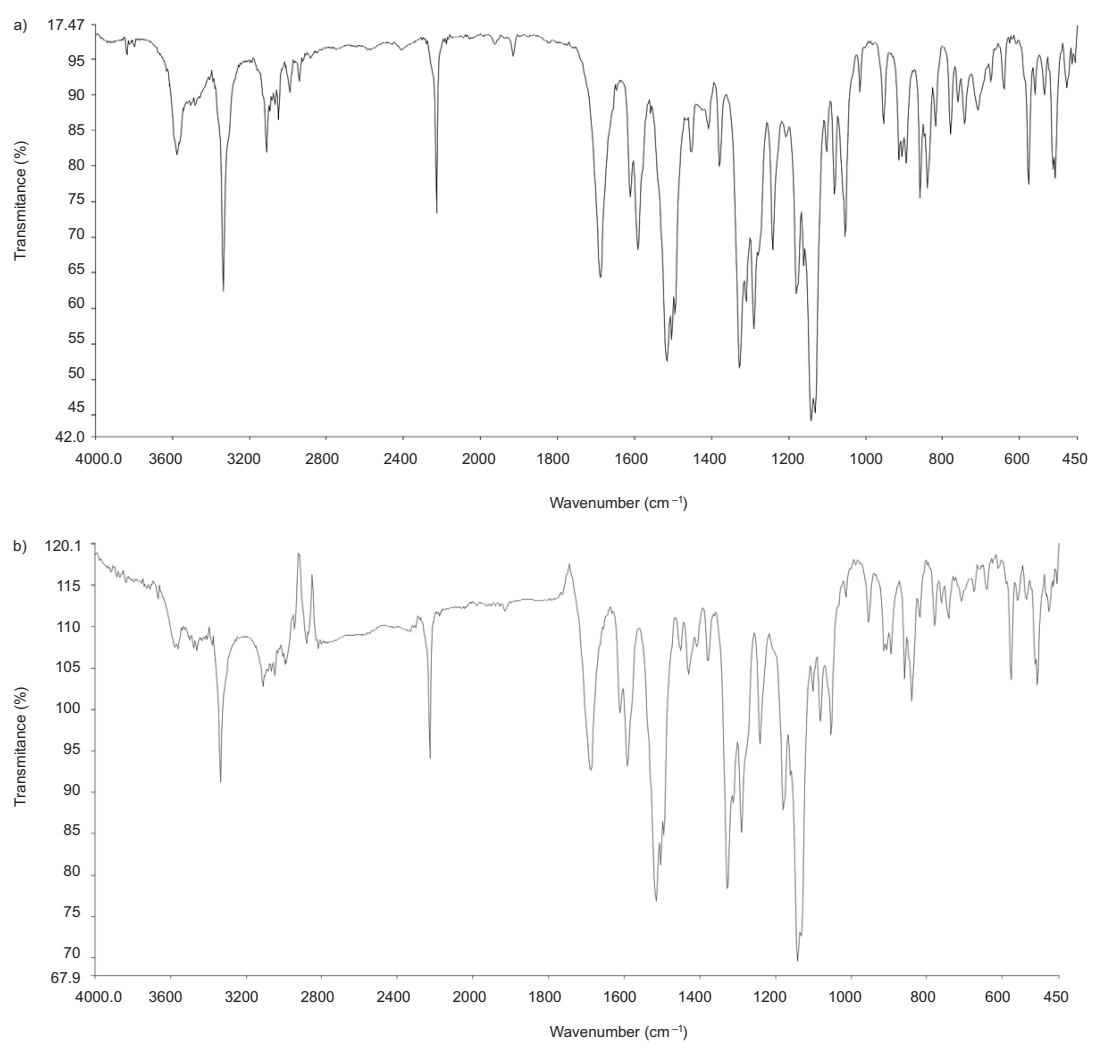

Fig. 7. FTIR of: a) raw bicalutamide, and b) LASPP bicalutamide microcrystals.

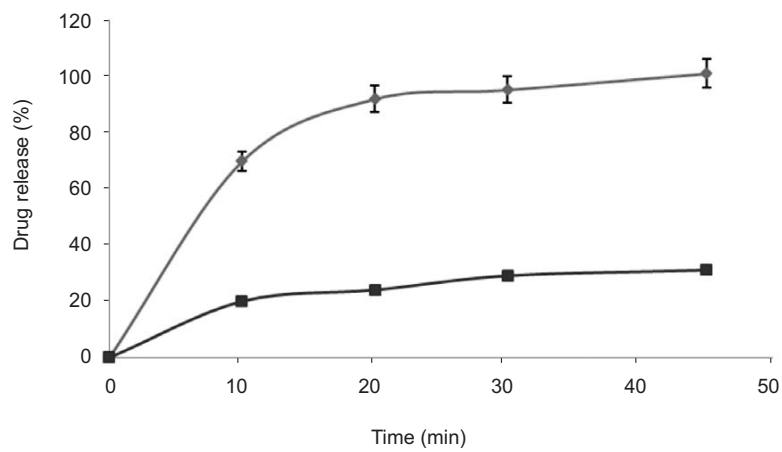

Fig. 8. Dissolution profile of raw bicalutamide tablets $(\boldsymbol{\bullet})$, and LASPP bicalutamide microcrystals tablets $(\bullet)($ mean $\pm \mathrm{SD}, n=3)$. 


\section{Dissolution test}

The test was performed as per FDA dissolution database guidelines and as reported in the literature. The results are shown in Fig. 8. The dissolution rate enhancement for LASPP bicalutamide tablets may be due to decrease in drug crystallinity.

\section{CONCLUSIONS}

In this study, microcrystal line particles of bicalutamide were prepared using a liquid antisolvent precipitation technique. The results illustrate that the antisolvent precipitation technique, in mild conditions, allows to prepare bicalutamide microcrystals with a reduced particle size and enhanced dissolution properties. In the process, HPMC E5 and Poloxamer 407 in aqueous phase were employed as a hydrophilic polymer and a surfactant, respectively, to inhibit crystal growth and aggregation, resulting in the formation of bicalutamide microcrystals. Dissolution rate was affected by the type of polymer or surfactant used and the concentration of either the polymer or the drug. The dissolution properties of the processed bicalutamide microcrystal particles were enhanced in comparison with those of the unprocessed drug by increasing the surface area caused by a reduction in particle size and a decrease in crystallinity. This process can be used in a cost effective manner for the production of immediate release formulations.

Acknowledgements. - Financial support of the University Grant Commission (UGC, Govt. of India) is gratefully acknowledged.

\section{REFERENCES}

1. D. R. Vega, G. Polla, A. Martinez, E. Mendioroz and M. Reionoso, Conformational polymorphism in bicalutamide, Int. J. Pharm. 328 (2007) 112-118; DOI: 10.1016/j.ijpharm.2006.08.001.

2. D. Wu, J. Yang, V. A. Nair, D. D. Miller and J. T. Dalton, Pharmacokinetics and metabolism of a selective androgen receptor modulator in rats: implication of molecular properties and intensive metabolic profile to investigate ideal pharmacokinetic chrecteristics of a propanamide in preclinical study, Drug Metab. Dispos. 34 (2006) 483-494; DOI: 10.1124/dmd.105.006643.

3. Y. Le, H. Ji, J. F. Chen, Z. Shen, J. Yun and M. Pu, Nanosized bicalutamide and its molecular structure in solvents, Int. J. Pharm. 370 (2009) 175-180; DOI: 10.1016/j.ijpharm.2008.11.025.

4. A. Abdalla and K. Mäder, Preparation and characterization of a self-emulsifying pellet formulation, Eur. J. Pharm. Biopharm. 66 (2007) 220-226; DOI: 10.1016/j.ejpb.2006.11.015.

5. I. Kanfer, Report on the international workshop on the biopharmaceutics classification system (BCS): scientific and regulatory aspects in practice, J. Pharm. Pharm. Sci. 5 (2000) 1-4.

6. P. Kocbek, S. Baumgartner and J. Kristl, Preparation and evaluation of nanosuspensions for enhancing the dissolution of poorly soluble drugs, Int. J. Pharm. 312 (2006) 179-186; DOI: 10.1016/ j.ijpharm.2006.01.008.

7. Y. Dong, W. N. Kiong, S. Shen, S. Kim and R. B. H. Tan, Preparation and characterization of spironolactone nanoparticles by antisolvent precipitation, Int. J. Pharm. 375 (2009) 84-88; DOI: 10.1016/j.ijpharm.2009.03.013. 
8. A. Balakrishnan, B. D. Rege, G. L. Amidon and J. E. Polli, Surfactant-mediated dissolution: contributions of solubility enhancement and relatively low micelle diffusivity, J. Pharm. Sci. 93 (2004) 2064-2075; DOI: 10.1002/jps.20118.

9. G. S. Jadhav and P. R. Vavia, Physicochemical in silico and in-vivo evaluation of danazole- $\beta$ cyclodextrin complex, Int. J. Pharm. 352 (2008) 5-16 DOI: 10.1016/j.ijpharm.2007.10.005.

10. I. Ilić, R. Dreu, M. Burjak, M. Homar, J. Kerč and J. S. Srčič, Microparticle size control and glimepiride microencapsulation using spray congealing technology, Int. J. Pharm. 381 (2009) 176-183; DOI: 10.1016/j.ijpharm.2009.05.011.

11. M. D. Moore and P. L. D. Wildfong, Aqueous solubility enhancement through engineering of binary solid composites: pharmaceutical applications, J. Pharm. Innov. 4 (2009) 36-49; DOI: 10.1007/ s12247-009-9053-7.

12. P. Zhang, H. Ye, T. Min and C. Zhang, Water soluble poly(ethylene glycol) prodrug of silybin: design, synthesis, and characterization, J. Appl. Polym. Sci. 107 (2008) 3230-3235; DOI: 10.1002/ app. 27450 .

13. Y. Le, H. Ji, J. Chen, Z. Shen, J. Yun and M. Pu, Nanosized bicalutamide and its molecular structure in solvents, Int. J. Pharm. 370 (2009) 175-180 DOI: 10.1016/j.ijpharm.2008.11.025.

14. R. P. Bagwe and K. C. Khilar, Effects of the intermicellar exchange rate and cations on the size of silver chloride nanoparticles formed in reverse micelles of AOT, Langmuir 13 (1997) 6432-6438; DOI: $10.1021 /$ la980248q.

15. J. Y. Zhang, Z. G. Shen, J. Zhong, T. T. Hu, J. F. Chen, Z. Q. Ma and J. Yun, Preparation of amorphous cefuroxime axetil nanoparticles by controlled nanoprecipitation method without surfactants, Int. J. Pharm. 323 (2006) 153-160; DOI: 10.1016/i.ijpharm.2006.05.048.

16. U. S. Food and Drug Administration, Dissolution Methods, Bicalutamide, FDA, Silver Sping (MD), Dec 15 2005; http:/ /www.accessdata.fda.(MD)gov/scripts/cder/dissolution/dsp_SearchResults_Dissolutions.cfm?PrintAll=1.

\title{
$S A \check{Z} E T A K$
}

\section{Tekućinski antisolvent postupak taloženja za modifikaciju topljivosti bikalutamida}

\author{
TARIQUE ALI MEER, KIRAN P. SAWANT i PURNIMA D. AMIN
}

Tekućinski antisolvent postupak upotrijebljen je za moduliranje topljivosti bikalutamida. Zbog vrlo slabe topljivosti u vodi i sporog oslobađanja, bioraspoloživost bikalutamida je mala i varijabilna. Cilj rada je poboljšati topljivost bikalutamida koristeći antisolvent precipitaciju. Kao hidrofilni polimer korišten je HPMC E5, a kao surfaktant Poloxamer 407. Variranjem količine polimera, surfaktanta i lijeka proces je optimiran. Nastali mikrokristali analizirani su uobičajenim instrumentalnim tehnikama za karakterizaciju materijala kao što su IR, DSC, SEM, XRD, veličina čestica, specifična površina i brzina oslobađanja.

Ključne riječi: bikalutamid, povećanje topljivosti, oslobađanje, tekućinska antisolvent precipitacija

Department of Pharmaceutical Sciences and Technology, Institute of Chemical Technology, Matunga, Mumbai-400019, India 